\title{
A Solid-phase Self-organized Catalyst of Nanopalladium with Main-chain Viologen Polymers: $\alpha$-Alkylation of Ketones with Primary Alcohols
}

\author{
Yoichi M. A. Yamada, Yasuhiro Uozumi * \\ Institute for Molecular Science, Myodaiji, Okazaki, Aichi 444-8787, Japan \\ uo@ims.ac.jp
}

Preparation of 2: To a solution of $1(1.68 \mathrm{~g} ; 4.0 \mathrm{mmol})$ in water $(100 \mathrm{~mL})$ was added a solution ${ }^{1}$ of $^{\mathrm{PdCl}} 2(709 \mathrm{mg} ; 4.0$ $\mathrm{mmol})$ and $\mathrm{NaCl}(4.68 \mathrm{~g})$ in water $(100 \mathrm{~mL})$ at $25{ }^{\circ} \mathrm{C}$, giving orange precipitates. The mixture was stirred at the same temperature for $1 \mathrm{~h}$. Purification by filtration (pore size: $1 \mu \mathrm{m}$ ), washing with water and drying at $5 \mathrm{~Pa}$ for $12 \mathrm{~h}$ afforded the insoluble product $2(1.77 \mathrm{~g})$ as an orange powder.

CP-MAS ${ }^{13}$ C NMR (232MHz; solid) $\delta 148.9,146.8,135.0,131.1,128.0,64.4$; IR (ATR) $v 3471,3117,3055,2920,2851$, 1636, 1611, 1436, 1421, 809, $768 \mathrm{c} \mathrm{m}^{-1}$; Anal. calcd. for $\left(\mathrm{C}_{18} \mathrm{H}_{16} \mathrm{Br}_{2} \mathrm{Cl}_{2} \mathrm{~N}_{2} \mathrm{Pd} \cdot 3 \mathrm{H}_{2} \mathrm{O}\right)_{\mathrm{n}}: \mathrm{C} 33.18 \%, \mathrm{H} 3.40 \%$, $\mathrm{N} 4.30 \%$, found: C $31.91 \%, \mathrm{H} 2.66 \%, \mathrm{~N} 4.33 \%$

${ }^{1}$ The solution was prepared by mixing $\mathrm{PdCl}_{2}$ and $\mathrm{NaCl}$ in water at $80^{\circ} \mathrm{C}$.

Preparation of nano-Pd-V 3: A solution of $\mathrm{NaBH}_{4}(450 \mathrm{mg})$ in EtOH $(75 \mathrm{~mL})$ was slowly added dropwise over $10 \mathrm{~min}$ to a suspension of $2(900 \mathrm{mg})$ in EtOH $(75 \mathrm{~mL})$ at $25{ }^{\circ} \mathrm{C}$, and the suspension was stirred for $6 \mathrm{~h}$. Purification by filtration (pore size: $1 \mu \mathrm{m})$, washing with water and drying at $5 \mathrm{~Pa}$ for $12 \mathrm{~h}$ gave nano-Pd-V $3(630 \mathrm{mg})$ as a dark brown powder.

CP-MAS ${ }^{13}$ C NMR (232MHz; solid) $\delta 130.9,128.8,63.9,56.8,52.8,42.1,31.5,15.5$; IR (ATR) v 3471, 31 17, 3054, 2920, 2851, 1636, 1436, 1236, 1090, $891 \mathrm{~cm}^{-1}$; Anal. calcd. for $\left(\mathrm{C}_{18} \mathrm{H}_{16} \mathrm{Br}_{2} \mathrm{~N}_{2} \mathrm{Pd} \cdot 3 \mathrm{H}_{2} \mathrm{O}\right)_{\mathrm{n}}$ : C 37.24\%, $\mathrm{H} \mathrm{3.82 \% ,} \mathrm{N} 4.82 \%$, found: C $37.51 \%, \mathrm{H} 3.72 \%$, N $5.08 \%$

General Procedure for $\alpha$-alkylation of the ketones 4 with the primary alcohols 5 in the presence of nano-Pd-V 3 and $\mathrm{Ba}(\mathrm{OH})_{2} \cdot \mathbf{H}_{2} \mathrm{O}$ : To a suspension of nano-Pd-V $3(10 \mathrm{mg})$ and $\mathrm{Ba}(\mathrm{OH})_{2} \cdot \mathrm{H}_{2} \mathrm{O}(63 \mathrm{mg})$ was added water $(42 \mu \mathrm{L})$, and the suspension was mixed by a vortex mixer for $1 \mathrm{~min}$ at $25^{\circ} \mathrm{C}$. Compound $4(0.334 \mathrm{mmol})$ and $\mathbf{5}(0.668 \mathrm{mmol})$ were added to the reaction mixture, which was stirred at $100{ }^{\circ} \mathrm{C}$ for $24 \mathrm{~h}$. For the reactions shown in Table 2, entries 412 , the mixture was purified by column chromatography (eluent: EtOAc/hexane) to give 6. For the reactions shown in Table 2, entries 1-3, EtOAc $(8 \mathrm{~mL})$ was added to the reaction mixture, which was then centrifuged at $4000 \mathrm{rpm}$ for 5 min. EtOAc layer was decantated and analyzed by GC to determine the GC yield of $\mathbf{6 a}$. To the residue was added water ( $8 \mathrm{~mL})$, followed by centrifugation at $4000 \mathrm{rpm}$ for $5 \mathrm{~min}$ and decantation of the aqueous layer to give a black powder that was dried at $5 \mathrm{~Pa}$ for 12 $\mathrm{h}$ and used for the next reaction as areusable catalyst.

1-cyclohexyl-3-(4-methoxyphenyl)propan-1-one (6g)

${ }^{1} \mathrm{H}$ NMR(500 MHz, CDCl $)_{3} \delta 7.09(\mathrm{~d}, J=8.5 \mathrm{~Hz}, 2 \mathrm{H}), 6.81(\mathrm{~d}, J=8.5 \mathrm{~Hz}, 2 \mathrm{H}), 3.78(\mathrm{~s}, 3 \mathrm{H}), 2.82(\mathrm{t}, J=7.6 \mathrm{~Hz}, 2 \mathrm{H}), 2.71(\mathrm{t}$, $J=7.6 \mathrm{~Hz}, 2 \mathrm{H}), 2.27-2.33(\mathrm{~m}, 1 \mathrm{H}), 1.58-1.81(\mathrm{~m}, 5 \mathrm{H}), 1.16-1.34(\mathrm{~m}, 5 \mathrm{H}) ;{ }^{13} \mathrm{C} \mathrm{NMR}\left(126 \mathrm{MHz}, \mathrm{CDCl}_{3}\right) \delta 213.3,157.9,133.5$, 129.2, 113.8, 55.2, 51.0, 42.8, 28.8, 28.4, 25.8, 25.6; IR (ATR) 2926, 2853, 1704, 1611, 1512, 1466, 1448, 1230, 1239, 1177, 1090, 1035, 890, 827, $630 \mathrm{~cm}^{-1}$; MS(EI(+)) $246\left(\mathrm{M}^{+}\right), 163\left(\mathrm{M}^{+}\right), 121(\mathrm{bp})$; HRMS (ESI(+)) calc for $\mathrm{C}_{16} \mathrm{H}_{22} \mathrm{O}_{2} \mathrm{Na}_{\left(\mathrm{M}+\mathrm{Na}^{+}\right)}$ 269.1518 , found 269.1526 
Registry Numbers; 1: 32168-10-8; 4a: 111-13-7; 4b: 821-55-6; 4c: 2550-26-7; 4d: 823-76-7; 4e: 98-86-2; 4f: 100-06-1; 5a: 111-87-5; 5b: 112-30-1; 5c: 100-51-6; 5d: 105-13-5; 6a: 45206-91-5; 6b: $18277-00-4$; 6c: 56741-23-2; 6d: 56705-47-6; 6e: $5396-91-8$; 6f: 43125-06-0; 6h: 1669-49-4; 6i : 1083-30-3; 6 j: 5739-38-8 
Figure S-1. SEM imaged of 3

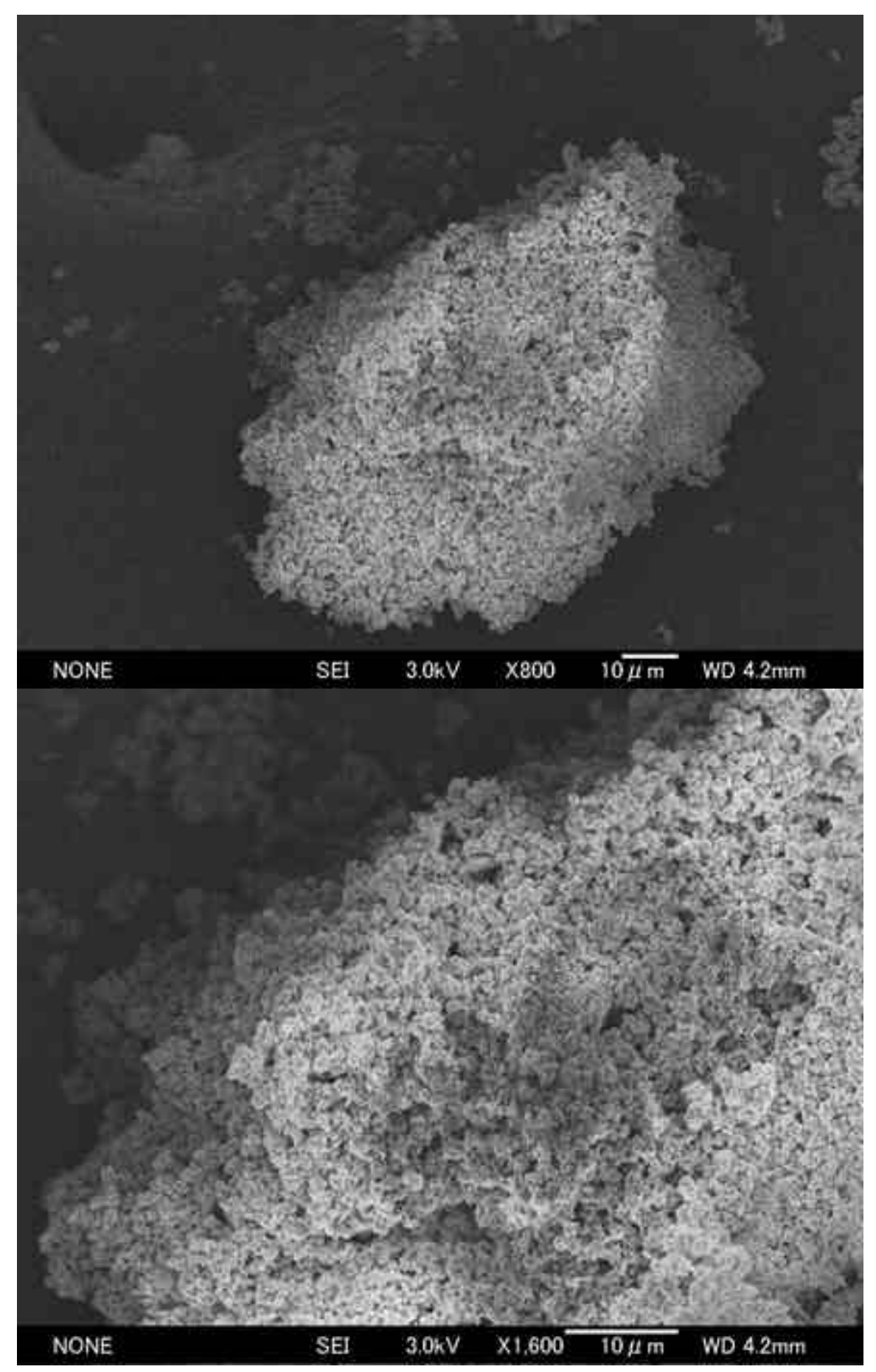




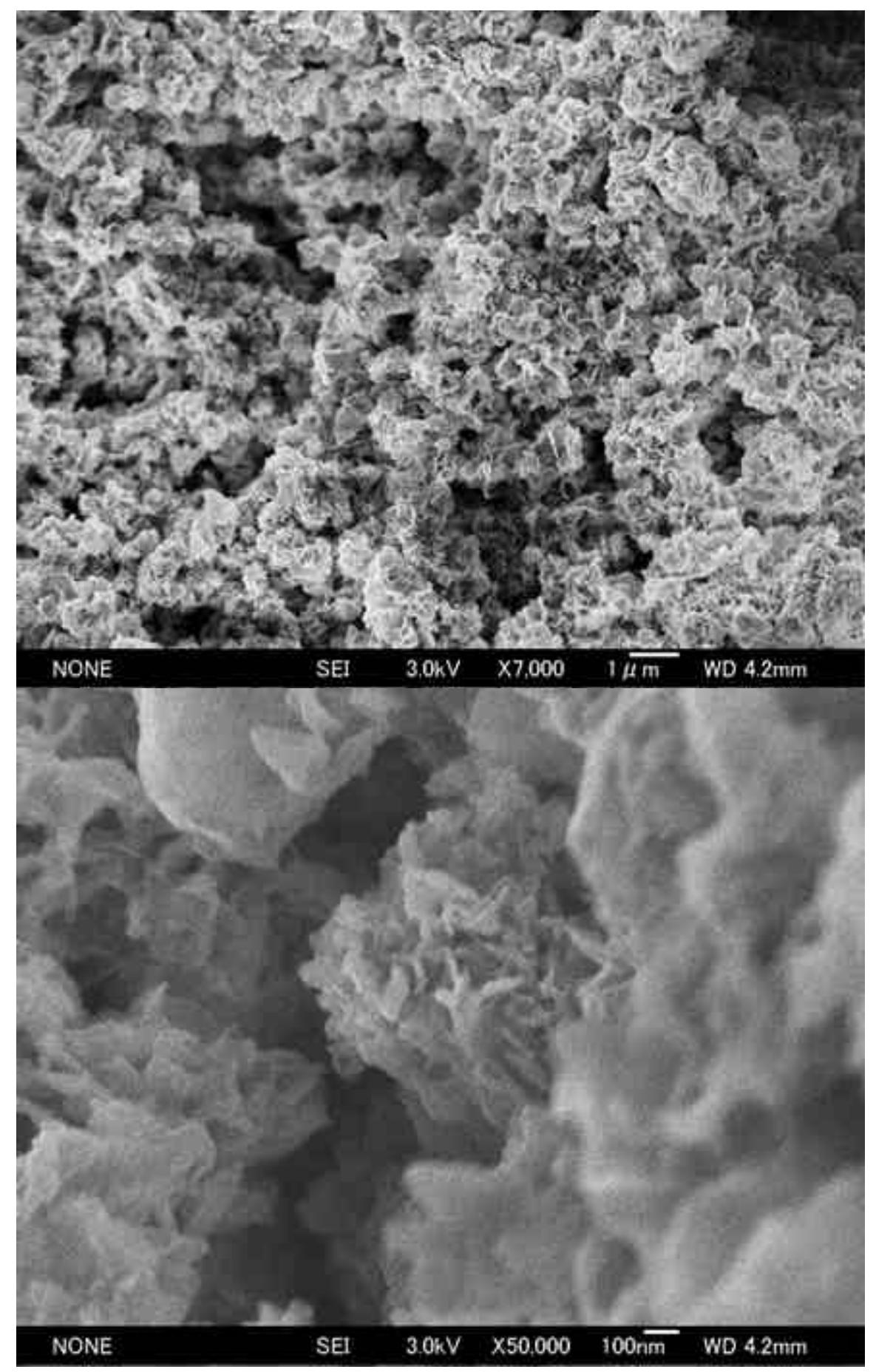


Figure S-2. TEM and STEM/EDS imaged of $\mathbf{3}$
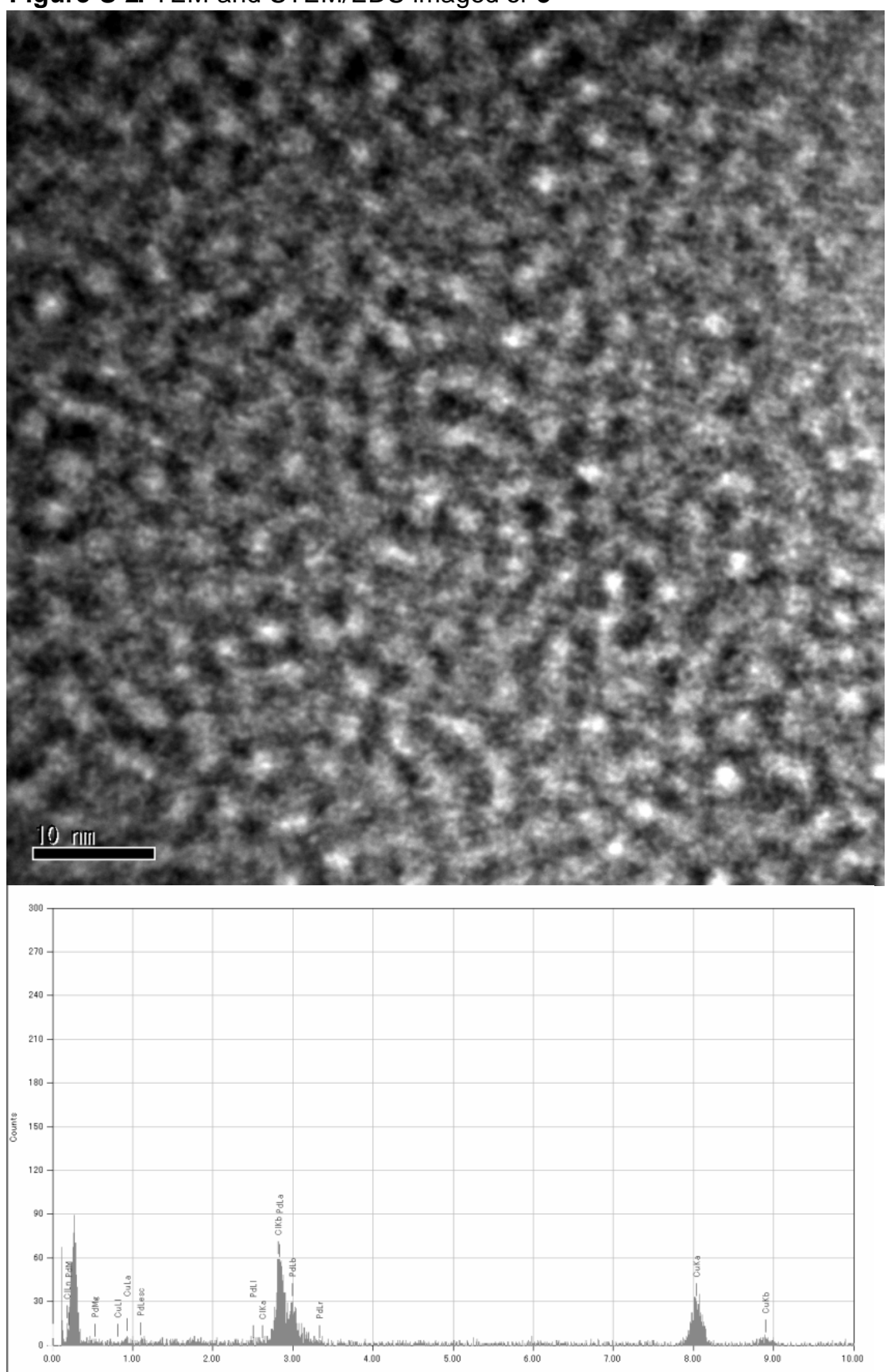

The STEM/EDS analysis was performed onto a carbon sheet having a Cu mesh. 
CP-MAS ${ }^{13} \mathrm{C}$ NMR (232MHz; solid) of 2

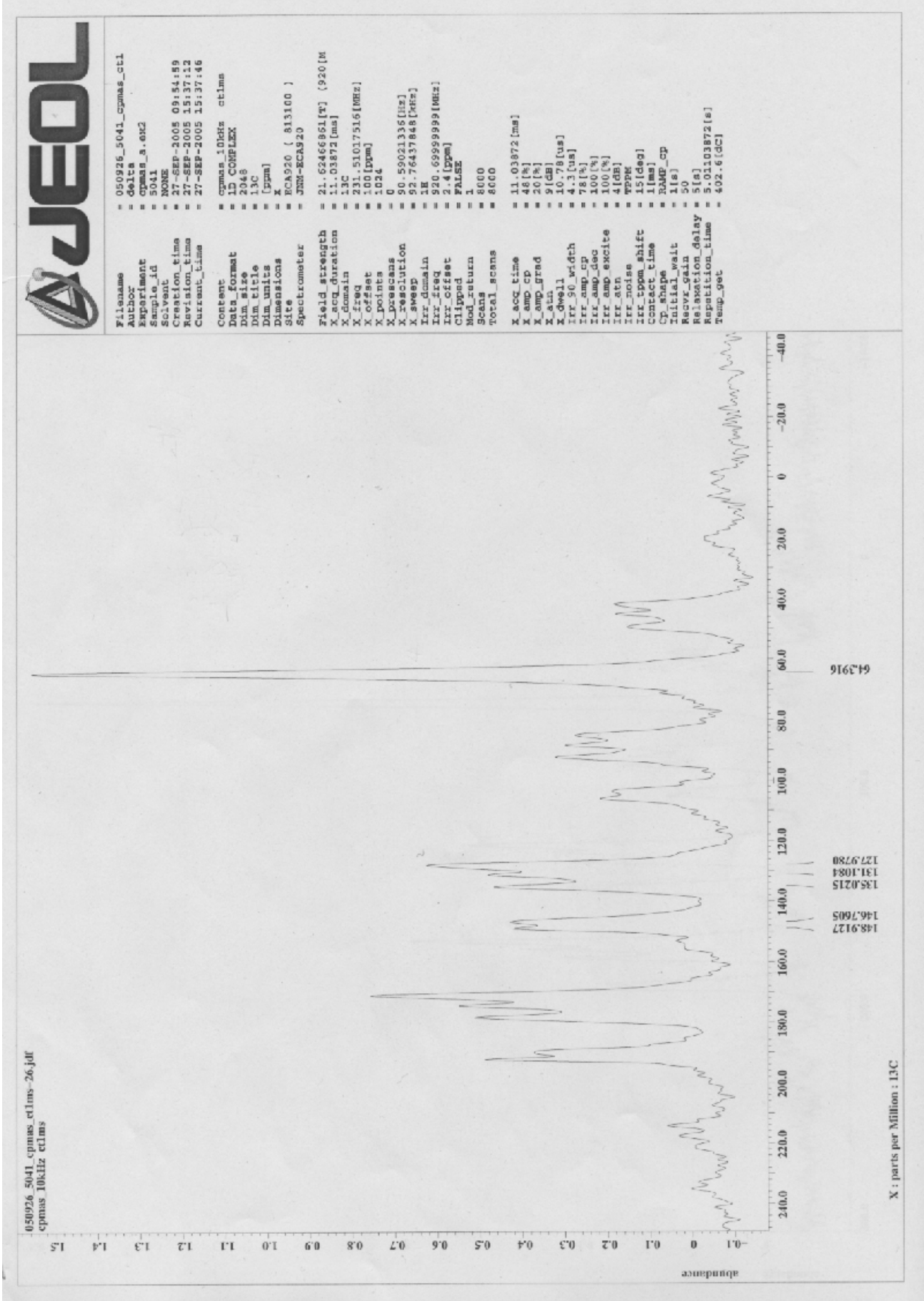


CP-MAS ${ }^{13} \mathrm{C}$ NMR (232MHz; solid) of nano-Pd-V 3

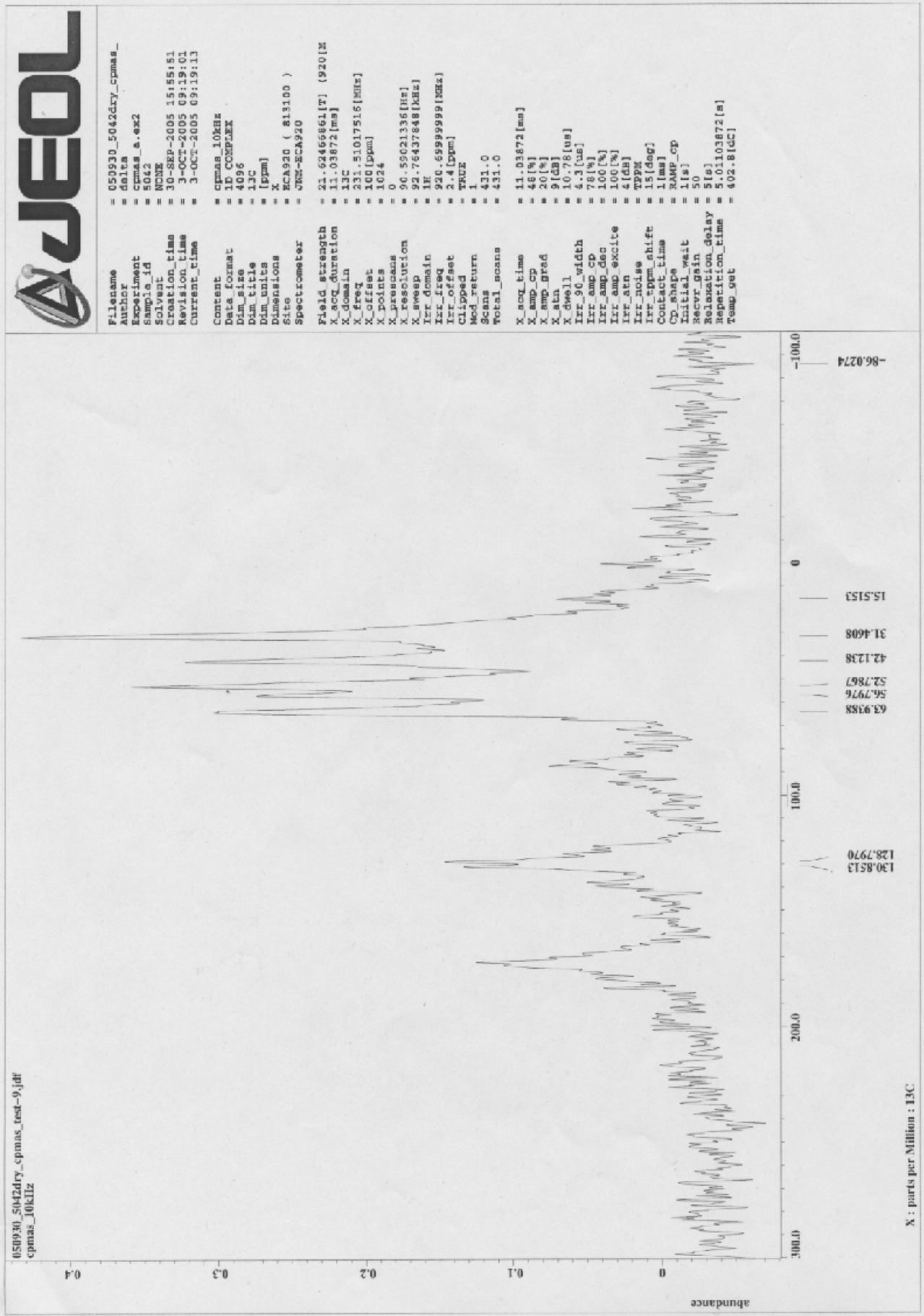




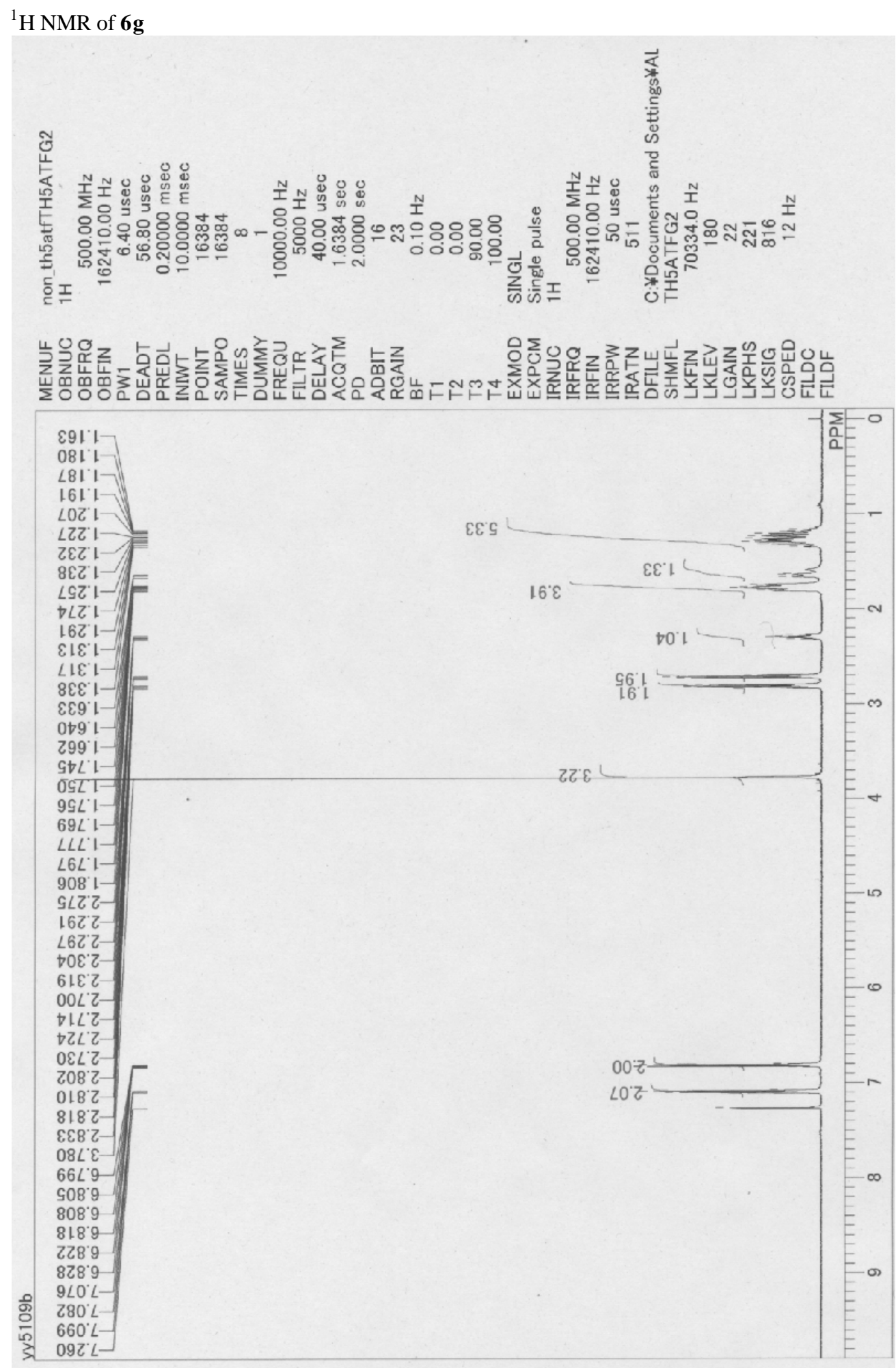




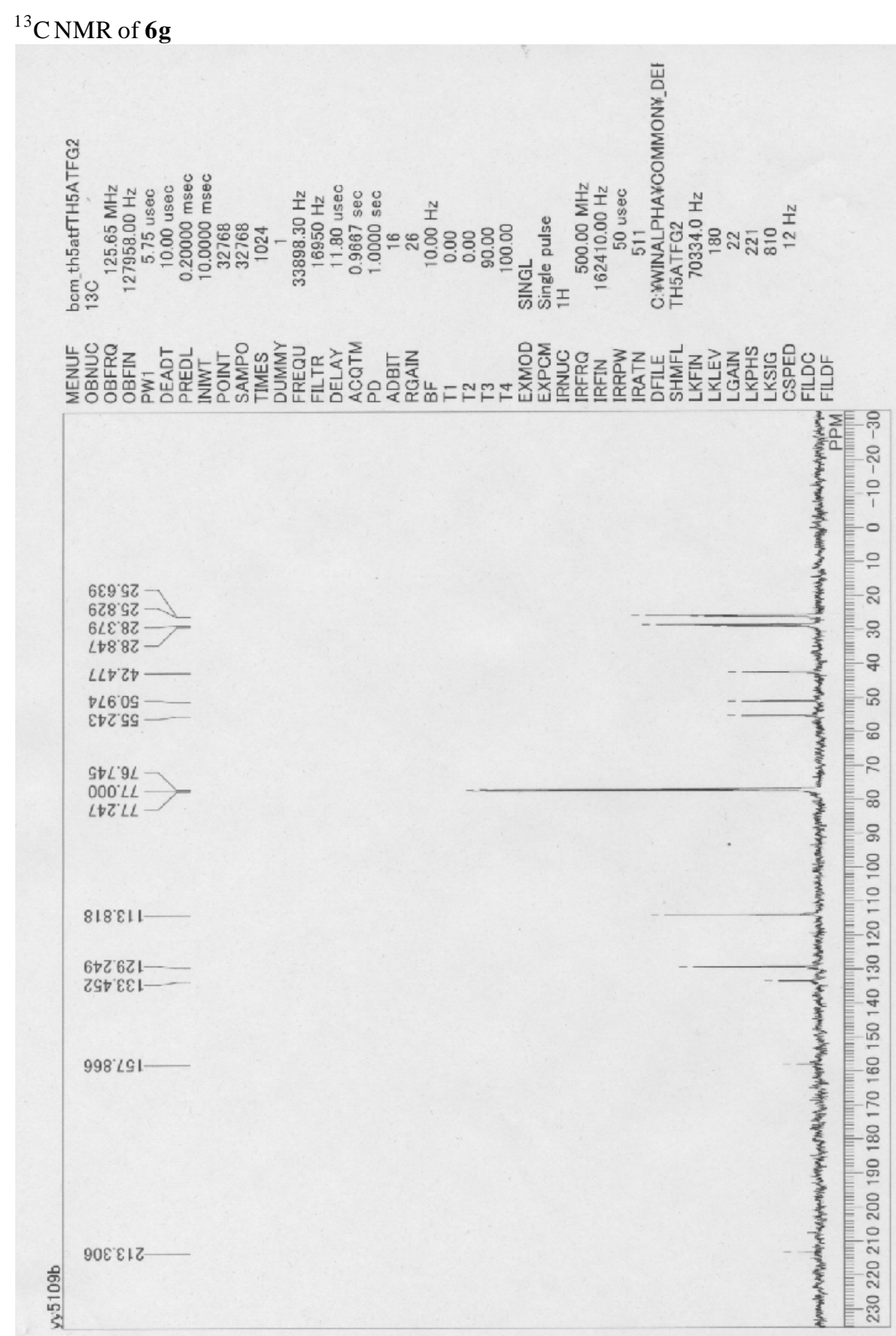

